Waller P. Wodchis

Brant E. Fries

Richard A. Hirth

\section{The Effect of Medicare's Prospective Payment System on Discharge Outcomes of Skilled Nursing Facility Residents}

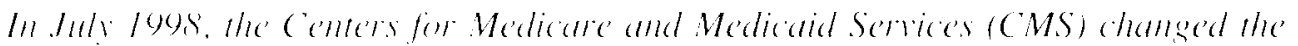

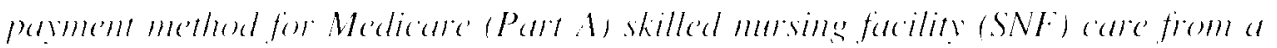

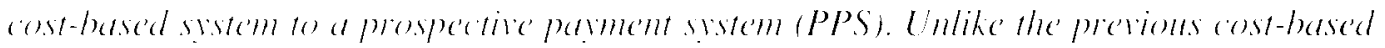

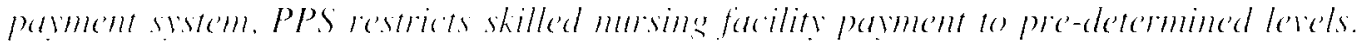

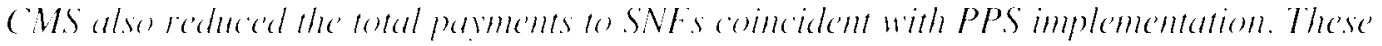

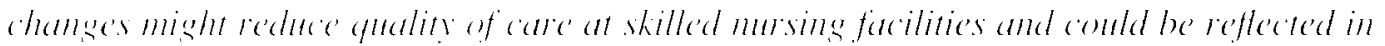

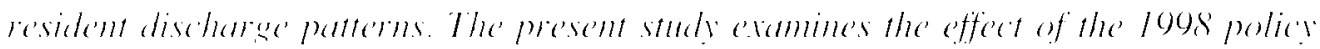
change an resident discharge onteomes. The results indicate that PPS reduced the retative

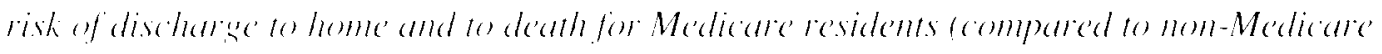

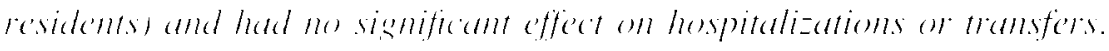

Between loged and logs. Medicare expenditures for stilled nursing facilits (SVF) services in creased from $\$ 1.7$ billion 10 \$ $\$ 10.2$ billion (centers for Medicare and Medicaid Services 20(14h). kadding to concerns ahoul the linancial sustamability of the benctit. To restrain this growth. in July logs the Centers for Medicare and Medicaid Services (c MS) begam a four-ycall phase-in process to introduce a prospective pay ment bsem (PPSi lo pay for Medicane Parl A SNI care ${ }^{1.2}$. Following the stecess of prosperelive payment in actle care seltings. (omeress mandated that ( MS develop and implement a PPS lo increatse control over Medicare SVI Expenditures. While PPS can be expected to con- strain Medicare expenditures. it maly also adversely alfeed patient care and outcomes.

The PPS policy implemented by the Medicane program introduced three important policy changes: 1) prospective payment: 2 ) calse-mix adjustment: and 3) a reduction in the average perdiem payment rates. Prior 10 1998. the Medicare program reimbursed $S N$ rs on the basis of their costs subject to per-diem limits on routine costs (room. board and routine musing) but with no limits on ancillary services (druges mathilitation therapy) (MedPAC 20(1)). In contrast to the cost-based payment alpproach. PPS provides morecontrol overexpenditures because the reim bursement for resident care is fixed betore the

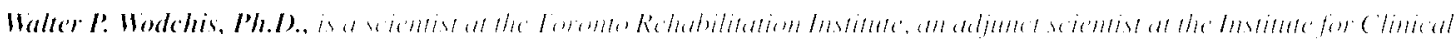

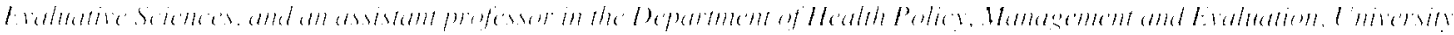

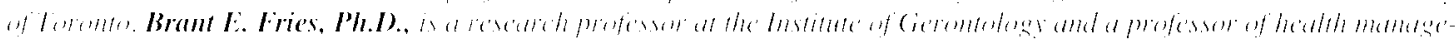

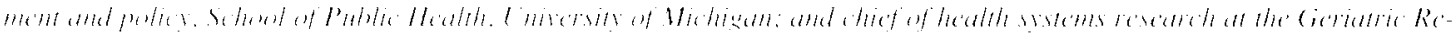

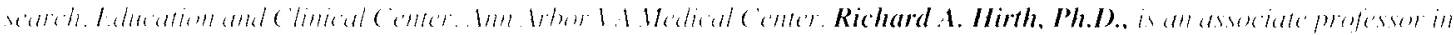

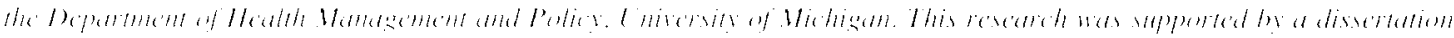

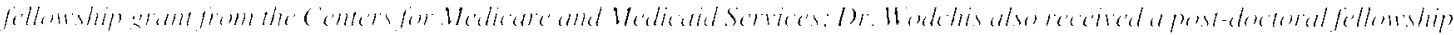

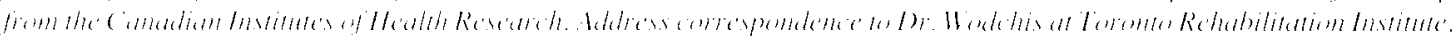

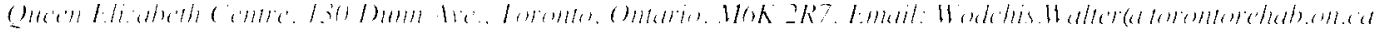


care is actually delivered. This approach creates new incentives to providers to limit costs to the predetermined payment level or less. A second significant attribute of the policy change was the introduction of case-mix adjustment. While the pre-determination of payment rates transfers the risk for additional costs to the facility. casemix adjustment allows higher reimbursement for more expensive residents. In addition. the 1998 rates, as implemented, reduced facility reimbursement from Medicare by an average of 17\% (CMS 1999). The overall impact was substantial. especially in facilities with a significant proportion of Medicare revenue.

The present study examines the elfect of the change in the Medicare payment system on SNF resident outcomes. Its purpose is to describe the incentives provided to SNF residents under PPS and to examine empirically the effect of PPS on one type of outcome: resident discharges from SNF care. As the payment change is applicable only to the Medicare resident population. the change in payment should be rellected only for Medicare residents and not for other residente in SNFs, namely Medicaid and privalte-pay residents. Nearly all facilities provide care for both Medicare (SNF) residents and non-Medicare (non-SNF) residents (in our presentation we focus on the Medicare population and refer to all facilities as SNFs). Non-Medicare residems in SNFs are a useful comparison group in the empirical analyses because they should be unalfected by the payment change but alfected by any common unobserved factors changing over time in the facility and the industry (e.g.. changes in facility staffing. growth in communily-based care alternatives).

The Medicare SNF benefit provides short-lerm. post-acute-care support and functional rehabilitation to help residents regain functional independence. Discharege to the community is an important outcome for rehathilitative care that is provided under the Medicare SNF benctit. Therefore, in this study, effectiveness of the Medicare program is measured by the likelihood of discharge to home. Faster discharge to home is also a component of efficiency for the Medicare SNF benefit: however. full assessment of Medicare program efficiency would require data on acule hospital stilys and home health benefits as well ats SNF care. If PPS improved the effectiveness of SNF care, the change to PPS should be alssociated with carlier community discharges and deferred hospitalization and death for Medi calre residents.

Discharge outcomes are a crude measure of the impact of a payment system change on SVF residents. Nonetheless. discharges can be measured with certainty and provide a summary outcome measure that may be indicative of the overall quality of care provided to SNF residents. Discharges to hospital or death are used commonly 10 indicale poor $S N F$ practices as are prolonged SNF stays (Arling. Williams, and Kopp 2000): Cohen and Spector 1996: Cohen-Mansfield et al. $1999)$. In contrast. discharges to home are generally seen as a positive outeome. so long as the resident is functionally ready for the transition (Arling. Williams. and Kopp 2000): Engle and Girancy 1993: Ilutl el al. 2001). Farlier discharege to the community can represent negative out comes if residents are discharged "quicker but sicker." We note the difference between hospital PPS (tived rate per stay) and SNF PPS (tixed rate per day): "quicker but sicker" is a bigeer concern in the former, supporting the view that community discharge is a good oukcome in the $\mathrm{SNI}$ context. This study examines whether PPS reduced the relative risk of discharges to home from SNFs for Medicare residents compared to non-Medicare residents.

\section{Provider Responses to PPS}

PPS does not necessarily reduce lacility revenues. lender PPS. the payment to a licility depends on both the composition of residents in the SNF ats measured by the resource ulilization geroups (RUG-III) case-mix system (Fries at al. 1994). and the palyment rate for each type of resident (MedPAC 200)2). While the attribution of revenue to residents within facilities is directly influenced by case-mix payment. the overall effect on facility reventer is dependent on the total revente stream from the Medicare program. Payment rates under PPS can be set to provide the same overall budget for Medicare SNF care. However, becaluse CMS believed that SNF costs were too high before the implementation of PPS. the payment rates were designed 10 provide real salvings for the Medicare program. Only 53 of the tolal 9.037 SNFs in the United Slates were expected to receive higher payments immediately following the PPS implementation (CMS 1999). With a re- 
duction in reventes imposed by PPS. there is an incentive for likeilities to reduce costs and potentially provide lower yuality of care. Becaluse the high level of payment from Medicare is thought (o) subsidize other SNF residents, Medicare reductions also could result in subsidy reductions and at decline in the quality of care hor non-Medicare residents.

Inder PPS, facilities still maty benefit if their facility costs are less than the predelemined PPS rates eren if these payments are low. At the same lime, inefficient or high-cost licilities may face operating deficils. In this contexe, elficiency refers to lower-cost care that achieves the same resident onteome. Unlite acule setlings where pay ment is prosided for an episode of care. SNFs are rembursed on a per-diem basis. Be callse the SNF PPS is a per-diem payment rather than an episole-batsed prospective payment, an incentive for carlice discharece only oceurs if the per-diem payment level is insulficient to meet lacility costs. Toreduce costs. factilities may require staff to spend less time caring for residents, or fitcilities maly use less expensive. lower-stilled statting inpus. Facilities also mal reduce activities that are not directls rembursed under the PPS. such as social and recreational programminge for residents. The latter changes may have deketerious effects on resident outcomes: functional inprovement may be impeded and discharge 10 the community maty be delayed. In addition. lower quality maly increatse the risk of hospitalization and death. For most Medicare residents. discharges to the communty indicate an cllicacious treatment outeome and we presume such outcomes 10 be preferable in most, if not all. cascs. If resident discharges to the community are negattively affected. and discharges to hospital or death increalse. the effectiveness of the Medicare SNF benefir will be compromised.

Each facility could be expected to respond diflerently w PPS. Facilities with a higher prevakence of Medicare residents would be the most responsive to the change in parment. Furthermore, o the extent that facilities provide differendial catre to residents based on payment soutce. changes in resident ontcomes would alfect Medicare residents more than pros ate paty or Medicand residents within the same lacilities.

The orfice of Inspector Cieneral has produced a number of reports examining the effect of PPS on Medicare resident access bo SNF care. All conclude that Medicare residents continue to have aceess to SNF care following the implementation of PPS (Oflice of Inspector (iencral 1999, 20(1). Angelelli and colleagues (20(12) similaty found minimal changes in SNF admissions. even among residents considered to be at high risk. This corroborates earlier Medicaid evidenee provided by Cohen and Dubay (1990). who found no difference in admission patterns for Medicaid residents in states with cost-based payment compared to states with prospective case-mix payment. However, an equally important evaluation criteria is the effect of PPS on resident outeomes.

There is very little empirical information regarding the effeed of payment on resident discharge oulcomes. Hutt and colleagues (20)1) analyzed data from the PPS demonstration project and found no effect of PPS on resident discharges to the community. However, the latter results were based on an experimental simple. Following the full implementation of PPS. it is not known whether potential cost-sar ing measures undertaken by facilities, such as lowering stalfing skill mix or reducing resident aletivity programming. had at negative effect on Medicare SNF residents. The present study provides more robust results with less opportunity for selection bias, by using datil from all residents in all SNIs in lwo states.

\section{Hypothesis}

With three simultaneous changes in the payment policy (prospective payment. calse-mix adjustment, reduced overall program spending), there are different possible provider behavional responses to PPS. We state our hypotheses in two frameworks: lirst holding quality of care constant: and then relaxing this assumption to allow quality to vary in response to the changes in payment policy. If quality is held constant. facilities will have a relatively lower per-diem profit from Medicare resident care. Whether there are any incentives to select residents for admission with particular care requirements depends on the extent to which the RLIG-III calse-mix system accurately reflects resident care costs. Nonetheless. on average, there is no explicit change in the incentive 10 retain or discharge Medicare residents who are admitted to the facility. Facilities maly be able to maintain profit margins by improving efficiency and delivering the same quality of calre al a lower cost. Here again there would be no change in 
resident discharges. However, if quality is reduced in response 10 al lower and lixed palyment. we expect that resident recovery will be impeded and residents will take longer to improve to a point where discharge to the community is pomsible. Thus reduced quality will delay resident discharges. If resident care is compromised communily discharges may be delayed while deaths and hospital dischareses maly be more prevalent and oceur sooner.

Thus, we hypothesize that the introduction of PPS will reduce the level of care provided by SNFs and resident outcomes will decline as a result. If resident care is compromised. community discharges will be delayed while deaths and hospital discharges will occur sooner.

For the present study, discharges to the commulnity are considered positive oulcomes: discharges to death and hospital are considered negative outcomes. We explore the changes in the rates of transfers between SNFs, without positing whether or not these transfers are beneficial. This particular interpretation of the appropriateness of discharges 10 each destination does have limitations. For example. it is possible that if care praclices were 10 deteriorate substantially following the implementation of PPS, the community could be pereeived as a relatively more attractive treatment location for Medicare residents than a SNF. Even if this were the case, however, discharges to the community would be a positive outcome relative 10 remaining in the poor quality facility.

\section{Methods}

\section{Orevien}

The outcome of interest for our analysis was time to discharge to home, to hospital, and to death. We used an observational study design, based on a natural experiment that occurred when the Medicare program changed palyment methods while obler payers for SNF care maintained their respective payment methods. We first examined a simple pre- and post-PPS comparison within the Medicare population. However. the effect of PPS in the latter analysis could have been confounded by other trends in the SNF mathet that at fected all residents, such as changes in the overall utilization and treatment patterns in SNFs. For example, the electronic submission of Minimum Data Set (MDS) assessments for all nursing home residents begin in July 1998. which coincided witle or was contemporary to the implementation of PPS for Medicare residents. Hence, the effece of PPS on Medicare resident discharge outcomes was identified using a difference-in-differences (D) strategy and a competing-risks havard re gression. The D2 srategy uned an indicalor variable to identify the dischares rish for Medicare residents compared to non-Medicatre residents. and a second indicator variable to identify the discharge risk in the post-PPS period compared to the pre-PPS period for all residems. The interaction between these two vartiables identitied the change in the diflerence between Medicane and non-Medicare residents that concided 1 ith the change to PPS payment. Changes in the relative risk of discharge between Medicare and nonMedicare residents before and after the change in payment were used to identify the effect of PPS on discharee outcomes and thas lo lest our hypothesis. The D2 strategy provides a means 10) avoid selection bias and collinearity of the tratment effect with contemporaneous changes that alfected all residents. Fixed resident. fiacility, market. and state attributes, and a continumus time trend were used as risk-adjustment controls. In addition, we estimated several specitication tests. including a market fixed-effects model that used a single indicator variable for each market, wather than market-level characteristics the number of facilities made it impossible to similarly identify lacility fixed effects).

\section{Dala}

This study used resident- facility-and marker level datal for all elderly SNF residents in Michi gan and Ohio in 1998 and 1999. These two states were selected hecause resident-level admission and discharge data were available electronicially for the periods both hefore and alter the change in the Medicare payment system. Information de tailing resident charateristics was ohtained from the Resident Assessment Instrument/Minimum Datal Set. The MDS is a comprehensive alssessment that includes information on resident demographic, functional, and diagnostic conditions as well as nursing and medical treatments. By congressional mandate. the MDS is performed for every SNF resident on admission. annually. and upon significant change in health stalls, with a reduced assessment performed quarterly (thall permits the RUG-III classitications to be 
deremined). MISS assessments ane collected and used to dekemine case mix for payment purposes using residem-specilic Rl Ci-lll scores. MDS data also now are used for the public Nursing Home ('ompare website (CMS 20)4al).

A lomeindialal databalse of all resident assessments was used for the present study. The MDS has been shown to be reliable and valid for clinical and health services reseatch purposes in several studics (Arling. Williams. and Kopp 20) Foredcrikisen. Tariot. and De Jomghe 1996: Hawes a al. 1095: Hut1 (1) al. 20(1): Morris. Fries, and Morris 1090; Morris ed al. 1907: Seatariet al. 1997). Fatcility charackeristics were oblatined from the online Survey Certitication and Reporting System (CSC AR) files. collected by slate licensure agencies burough the SNF cortitication process. The oSC AR dalabase includes all Medicate- and/or Medicaidecertified SNles in the fonited States and is commonnly used in studies to measure pro-

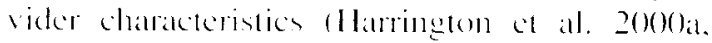
2000b: Harringene et al. logsi. In addition. the C MS medicall wales index is used to account for differential Medicare reimbursements provided to facilises in difterent markets.

\section{Olltermle' larial)les}

The outcome of interest in the regressions is time fo discharge on cach possible destination as recorcled on the MDS discharese raching form. The Medicare SNI benclit provides up a 100 days of S.VF care (with an adelinional copalyment of $\$ 101.50 .00$ about 30 , $10.50 \%$ of the total cost. required fom resielents after 20 days). The period ofoleservation for the present study was limited to the lirse 120 dats of S.VF calre. Lomeser-stay resideme were comsidered here as "not discharged" during the periol under study. Pant studics of mursing home discharges have used a variely of periods from ion through 180 days lEngle and

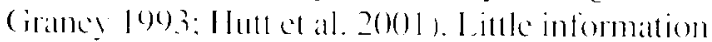
was los by limiting the period of observalion bocaluse most Medicare benediciaries are discharged by day 120 (carber and Mareardy 1003): data for the present study indicalle that $70 \%$ of Medicare residents were discharged before 120 days. The dedined observalion period also limits biascallsed by interations belween discharge onteomes and lime. We chose a period slighty longer than the 10()-day Medicare benedit limit in an seflont to idenlily as many dixcharges as possible and not wo exclude discharges slighty outside the benefit pe- riod. Any number of circumstances including transpotation requirements, home aceessibility issues. and the availability of adequate support systems could slighty delay a dischallege. while ecnsoring these observations would add measurement error in delemining resident discharge pattems. Sensitivity analyses examined the impact of using a $10(0$-day rather than a 120 -day exposure period.

Four dependent variables were comstructed to represent the dime of discharge to the community. to an alcuke care facility, 10 death, or to manster to another nursing care facility within the first 120) days of a SNF staly. Residents still remaining in the SNI beyond 120 days were coded as " not dischareged" (cemsored).

\section{Independem lariables}

We follow an "intention to tratl" paradigm by presuming that outcomes achieved by the 120th day are attributable to the care provided under the intial payer for the SNF stay. Moreover. changes in payer are relatively uncommon during the first $10(0$ days of a Medicare SNF stay. The payment source for resident care wats jelentilied from resident MDS admission assessments.

Reimbursement under PPS began for carch latcility with the first cost-reporting period after July 1. 1908. The exception was for facilities that changed ownership or began operalion alles 1994. In the latter lacilities. PPS was unitormly effective als of Jall 1. 1999. The fact that PPS "lat elfective lor facilities at irregulat periods provides additional protection agams hials from temporal changes in the SNF market. To identily the eflective date of PPS, the cost-reporting date for sach fakility was obtained from OSC $\triangle R$ chata. The PPS payment period indicalor variable was coded ats " " for all residents in the facility atter the firse cost-reportine period following July 1 . logs, and "()" for assessment data before the edfective date. The interaction of Medicate patyment and the PPS period indicator identified the treatment group (i.e.. Medicane residents after the change to PPS payment).

Several resident charateristics were included in multivariate analyses to anoid the possibility of omitled variable bias or confounding that would occur if any resident chatracteristics or treatments on admission were systematically related to both Medicare payment on admission and resident discharge. Resident demographic chatateristics included in all analyses were admission ages. 
gender, admission from hospital, and admission from SNF. Early models developed for this study included an extensive array of resident diagnoses and conditions. However. becallse most conditions had a trivial effect on discharges (relative risk within range of .98 to 1.02 ) and were not correlated with payment variables (coefficients were monitored), the list of conditions wals reduced to simplify the analysis. Resident diagnoses and conditions included in the final model are: $\mathrm{Al}$. heimer's disease: the presence of pressure sores: whether the resident had a recent fall: whether the resident was bedfast: physical and cognitive functioning: and the RUG-III case-mix index. Physical functioning was mealsured with the Activities of Daily Living (ADL) Hicrarchical Scale. This scale. ranging from () (fully independent) 10 6 (fully dependent) is based on resident capacity in personal hygiene. locomotion, toileting, and cating. and has been validated against the functional independence measure (Morris, Fries, and Morris 1999: Williams el al. 1994: Williams el al. 1997). Cognitive function was assessed usinge the Cognitive Pertormance Scale (CPS). This scale meatsured cognition ranging from () (fully intac1) to 6 (totally dependent) and hats been validated against the Folstein Mini Mental State Exam (Hantmaier el all. 1995: Merris et al. 1994). ADL and CPS scores were cach collapsed into three caltegories of impatrment representing broad levels of functional capacity: scores of () and 1 are atsocialed with independence: scores of 2. 3, or 4, are associated with moderate levels of imparment: and scores of 5 or 6 are associated with severe impairment or total dependence. Three treatments also were included as control vartiables in the linal model beciuse they could alfect discharge and might be correlated with palyment source on admission: indwelling callheter: tube feeding: and oxygen therapy. Finally, the RUG-III case-mix index wals used 10 account for additional resident hederogeneily. This inder ranged from .39) to 3.68 and provides a cardinal measure of the overall resource intensily required to calre for the resident. The inder wats the weighting fictor used to determine Medicate reimbursement for resident care. Ilere it provided a control for differences in care resources ansocialed with a given resident on admission to the facility. To the extent that the case-mix index reflects resident severity, the index captured additional resident heterogeneity on admission to the facility.
Facility characteristics may also play an important role in the care and discharge patkems of residents (Braun 1991: cohen and Spector 1096: Porell al al. logs). The most proximal os CAR fiacility survey infomation was linked to MDS. Facility-level variables from OSCAR included in the model were: the oceupancy rate; the percentage of lacility residents who were Medicare: the percentage who were Medicald: whether the lacility was a for-protit organization; and whelluer the facility was hospital-based. Stalling ratios per 100 residents were calculated separately for nurses, health aides, and the combination of licensed practical murses (I.PN) and licensed vocational nurses (l,VN). Market-level competition was addressed by calculating a tratnsformed Hertindahl Index of Competition. The formula for the calculation used is one minus the sum of the market shatres squated. The most competitive markets have index values near one, while the keast competitive matreds have index values near zero. Consistent with prior research. we used number of beds lo calculate the mather share of lacilities and chose the county as the SNF marked area (Banas/ak-lloll, Zimn. and Mor 1996: Cohen and Spector 1996: Ciralbowshi 2001a. 200/b). The mathet-level wate index was obtaned from the CMS PPS rule w control for area wage costs. Weights were associalted with individual metropolitan statistical areas (MSAs) and state-lewel weights were applied to SNFs in non-MSA areas. These weights were used to adjust the Medicate patyment rates for SNFs under PPS.

Finally, al comtinuous tume variable was included to capture the emporal trend in discharge patterns for all SNF residents. The time variable was calculated as time since Janually 1908 . the start of the study period.

\section{Studs Poprutaturn}

The enal number of Medicare. Medicald, and private-pay SNF admissions in Michigan and ()hio in 1998 or 1999 was 221.660). Lexs thatn $1 \%$ of these admissions ( $n=1.039)$ were deleded becautse of missing data. To ensure a common exposure period for residents, we excluded a further 39.41 .5 residents who were admitled in the timal 120 days before the study end datle. Facilities not certified as SNFs also were excluded from the analyses $(24.318$ residents). Some residents. 
particulatyly those discharesed to a hospital. hatd more than one sive stay. In these cases, a simgle random SNF staly Wats selected: including multiple SNF dischareses Hould introduce correlated entors bemeen observations from the same resident. We cxamined the semsitivity of results to selecting a random versus the first observed resident staly Selecting the first revident stay introduces a bias toward SNI statsocenring carly in the study period prior to the implementition of PPS ne discuss these resules ats semsitivity analyses). The final study population is 106.126 resident admissions.

\section{Inalyses}

The primary objective of the analyses was to assess the effect of PPS on SNF discharge outcomes. The analyses used a competing-risks hazard model to estimate the relative risk of discharge based on resident admission information. The risk period for residents in this study began with entry to the facility and continued for 120 days. The risk of discharge in the first 120 days was assumed to be dependent on admission characteristics, including the source and method of payment. Four models were used to examine the effect of PPS on resident discharge to the community, to hospital, to death, or to transfer, respectively. In each model, residents who were not discharged to the destination of interest were treated as censored either because they were discharged to another destination or were not discharged before 120 days. This form of hazard model is referred to as a "competing-risks" hazard model because it estimates the likelihood of an event occurring before another, competing event occurs. The primary advantage of this model was that it provided a standardized means to account for different potential discharge destinations and for observations where discharge was not observed by censoring these observations. The hazard model estimated the following equation:

$$
\begin{aligned}
h_{i}(t)=h_{0}(t) \exp \left\{\beta_{1} * \text { Medicare }_{i}+\beta_{2} * \operatorname{PPS}_{i}\right. \\
\left.+\beta_{3} *\left(\text { Medicare }_{i} * \mathrm{PPS}_{i}\right)+\underline{\mathbf{Z} \gamma}\right\}
\end{aligned}
$$

where $h_{0}(t)$ represented the baseline hazard for all residents; $i$ indexed each resident observation; $\beta_{1}$ captured the effect attributable to Medicare; $\beta_{2}$ captured the change in discharge coincident with the PPS period; and $\beta_{3}$ captured the effect of PPS on the existing difference between Medicare and non-Medicare residents. $\boldsymbol{Z} \gamma$ was an array of ex- ogenous risk-adjustment factors, including fixed resident facility market and state variables and a continuous time trend. In the Medicare-only analysis, $\beta_{1}$ and $\beta_{3}$ were constrained to be zero and $\beta_{2}$ identified the change in discharge outcomes coincident with the post-PPS period.

An important advantage of the havad model Was that it estimated the likelihood of discharge to each destination. conditional on continuous residence in the SNF from admission until the observed assessment. Thus, when point estimates were created. the model eomtrolled for the ellect of a given length of stay and the underlying propensity for discharge. Furthermore, the proporlional-harard model did not assume a constant underlying risk of dischatrese. The havard model thus estimated the effect of PPS on ending SNF stays with a discharge 10 each destination: relattive-risk estimates measure the effect of PPS on the exit rate from a SNF stay for residents dischareed to each destination.

\section{Results}

The discharge destinations and length of staty on discharges are depiced in Table 1 for all residents discharged from SNFs within the first 120 days. Results are shown for Medicare residents and for non-Medicane residents for admissions before and alter the implementation of PPS. Sixty-one pereent of all resickents were discharged during the liest 120 datys of their SNF staty. Nearly half the discharged residents went home: about onesixth were hospitalized. Thirteen pereent of all admissions died within 120 days in the facility and 9\% were transterred to another non-alente institutional facility (nearly all transfers were 10 other nursing facilities). More residents were discharged in the posi-PPS period and discharges oscurred carlice in the post-PPS period for both patient groups. Most residents were admited with Medicare as their palyment source. Medicare residents had a higher prevalence of discharge to home and to hospital than non-Medicare residents. while deaths and transfers in the first 120 days were similar for the two groups. Pre- and post-PPS changes in discharge prevalence and length of slaty were in the same direction for bolh Medicare and non-Medicare residents. The univariate results cannot identify whether changes in resident discharges following the implementation of PPS payment were experienced equally by all residents, were 
Table 1. Summary discharge characteristics: prevalence of discharge destination in first 120 days and mean length of stay (LOS) in days at discharge

\begin{tabular}{|c|c|c|c|c|c|}
\hline \multirow[b]{2}{*}{ Discharge destination } & \multicolumn{2}{|c|}{ Medicare stays } & \multicolumn{2}{|c|}{ Non-Medicare stays } & \multirow[b]{2}{*}{ Overall } \\
\hline & Pre-PPS & Post-PPS & Pre-PPS & Post-PPS & \\
\hline$N$ & 37,015 & 39,140 & 16,469 & 13,502 & 106,126 \\
\hline Home $(\%)$ & 32 & 37 & 10 & 17 & 29 \\
\hline Mean LOS (days) & $30.7(22.5)$ & $27.3(20.9)$ & $29.3(21.8)$ & $27.3(20.8)$ & $28.7(21.6)$ \\
\hline Hospital $(\%)$ & 10 & 12 & 4 & 6 & 10 \\
\hline Mean LOS (days) & $36.0(25.5)$ & $30.8(24.2)$ & $41.3(28.6)$ & $38.6(27.9)$ & $34.1(25.6)$ \\
\hline Death $(\%)$ & 13 & 15 & 10 & 13 & 13 \\
\hline Mean LOS (days) & $38.6(28.3)$ & $32.8(27.6)$ & $47.2(30.4)$ & $44.9(30.7)$ & $38.0(29.0)$ \\
\hline Transfer $(\%)$ & 9 & 9 & 8 & 10 & 9 \\
\hline Mean LOS (days) & $41.2(28.7)$ & $33.6(27.4)$ & $44.9(29.5)$ & $43.4(30.4)$ & $39.1(28.9)$ \\
\hline Not discharged $(\%)$ (censored) & 36 & 26 & 68 & 54 & 39 \\
\hline
\end{tabular}

Note: Standard deviations are in parentheses.

due to changes in the resident populations. or resulted from the change in the payment system. Multivariate analyses were required to control for resident. facility, and market characteristics not identitied in the summary results.

Summary resident, facility. and market characteristics are presented in Table 2. About 1wothirds of all residents were admitled from the hospital and the most prevalent age cohort was 7.5 to 84 years old. Over half of all residents were totilly dependent in ADL function. Jus over $40 \%$ of residents were independent in cognitive performance. and about the same proportion were moderately impaired.

The most common conditions on admission were a recent fall $(45 \%)$ and pressure uleers $(43 \%)$. and the most common diagnosis was stroke $(21 / \%)$. Sixty-four percent of facilities were for-protit and the average occupancy rate was $8.3 \%$. Medicare residents constituted one-filith of the $\mathrm{SNF}$ population at any given point in time. whik the longer-stay Medicaid residents dominated fat cilities with $56 \%$ of residents. In Michigan and Ohio facilities, there were about 14 full-timeequivalent (FTE) registered nurses. 17 FTE licensed practical or vocitional muscs. and 4.5 FTE health aides per 100 residents. The transformed Hertindahl index average of 86 slggests that SNF markets in these two states were quite competitive.

Figures 1 and 2 display the unadjusted KaplanMeier survival and hazard curves depicting the duration of SNF stays before a discharge home. Curves are shown hefore and after PPS for the Medicare and non-Medicare populations. The figures show that non-Medicare residents have longer SNF stays (also note the spike in the hatard rate only for Medicare beneficiaries all aboul the 100 -day benetit limit). The figures also show thall both Medicare and non-Medicare populattions were more likely to be discharged home in the post-PPS period and thus survival in the SNF was lower. The survival curves ate thus lower and the havard curves higher for both populations in the post-PPS period. Multivariate analysis was used to examine whether this change was larger for the Medicare population.

All the variables shown in Table 2 as well at a continuous linear time arend were included as covariates in the multivariale havard regressions to control for resident. facility. and market fictom that might be comelated with dischatres outcomes and palyment. Relative-risk estmalles and signiticance levels from the havard extimation are presented in Table 3. To simplify the exposition of the effect of PPS. only payment characteristics are presented in Table 3 (full model results are provided as appendices). Hazalrd relative-risk $(R R)$ estimates indicate the relative rish arelative 10) absence of the indicator) of discharge to each destination al a point in time. eiven that the resident has resided in the SNF until that point in time.

The first row of Table 3 presents the RR between the post-pPS period and discharges for Medicare residents only. The resules indicate a RR of 1.05 for discharge to home within 120 days compared to the pre-PPS period. Deaths were less likely for Medicare resilemes in the post-PPS period with a RR of only .92.

Comparing the differential change in the discharge duration for Medicare residents compared to mon-Medicare residents tests the hypothesis 
Table 2. Summary of independent variables

\begin{tabular}{|c|c|}
\hline Variable & $\begin{array}{l}\text { Percent } \\
\text { or mean }\end{array}$ \\
\hline$N$ & 106,126 \\
\hline \multicolumn{2}{|l|}{ Payment characteristics on admission } \\
\hline \multicolumn{2}{|l|}{ Payment } \\
\hline Private pay & $15 \%$ \\
\hline Medicare & $72 \%$ \\
\hline Medicaid & $13 \%$ \\
\hline Post-PPS period & $50 \%$ \\
\hline Medicare * Post-PPS (D2 estimator) & $37 \%$ \\
\hline \multicolumn{2}{|l|}{ Resident-level variables on admission } \\
\hline Male & $32 \%$ \\
\hline Admitted from hospital & $68 \%$ \\
\hline Admitted from nursing facility & $5 \%$ \\
\hline \multicolumn{2}{|l|}{ Age } \\
\hline $65-74$ & $24 \%$ \\
\hline $75-84$ & $45 \%$ \\
\hline $85+$ & $32 \%$ \\
\hline \multicolumn{2}{|l|}{$\mathrm{ADL}$} \\
\hline Independent $(\mathrm{ADL}=0,1)$ & $10 \%$ \\
\hline Impaired $(\mathrm{ADL}=2,3,4)$ & $37 \%$ \\
\hline Totally dependent (ADL = 5,6) & $53 \%$ \\
\hline \multicolumn{2}{|l|}{ Cognition } \\
\hline Independent $(\mathrm{CPS}=0,1)$ & $42 \%$ \\
\hline Impaired $($ CPS $=2,3,4)$ & $40 \%$ \\
\hline Totally dependent $(\mathrm{CPS}=5,6)$ & $18 \%$ \\
\hline Recent fall $(<180$ days $)$ & $45 \%$ \\
\hline Cerebrovascular accident (stroke) & $21 \%$ \\
\hline Alzheimer's disease & $9 \%$ \\
\hline Bedfast & $9 \%$ \\
\hline Pressure ulcer & $43 \%$ \\
\hline Indwelling catheter & $17 \%$ \\
\hline Feeding tube & $9 \%$ \\
\hline Oxygen therapy & $23 \%$ \\
\hline RUG-III case-mix index & $1.99(.96)$ \\
\hline \multicolumn{2}{|l|}{ Facility-level characteristics $(N=1,450)$} \\
\hline Total beds & $152(101)$ \\
\hline Occupancy rate & $83 \%$ \\
\hline Facility is hospital-based & $12 \%$ \\
\hline For-profit ownership & $64 \%$ \\
\hline Chain membership & $55 \%$ \\
\hline Percent Medicare residents & $20 \%$ \\
\hline Percent Medicaid residents & $56 \%$ \\
\hline Registered nurses / 100 residents & $13.9(18.1)$ \\
\hline LPN \& LVN / 100 residents & $16.8(12.6)$ \\
\hline Health aides / 100 residents & $44.7(22.3)$ \\
\hline \multicolumn{2}{|c|}{ Market-level and state characteristics $(N=160)$} \\
\hline Market competition & $.86(.18)$ \\
\hline Market wage index & $.94(.09)$ \\
\hline Ohio & $59 \%$ \\
\hline
\end{tabular}

Note: Standard deviations are in parentheses. for this study. Discharges for Medicare and nonMedicare residents were subject to changes in the availability of community supports and alternattive care settings throughoul the study period. Quality improvement activities within SNFs were also expected to affect all residents in the facility. However, only Medicare residents were directly affected by the introduction of PPS. Thus it is the differential change in discharges that measures the effect of PPS on Medicare resident onteomes and provides a test for our hypothesis. This effect is measured by the interaction between the Medicare payment source variable and the post-PPS period.

The full sample results shown in Table 3 indicalle that the post-PPS relative risk for discharege to home for all residents was 1.16 times that of the pre-PPS period risk. Thus, while the Medicare population alone experienced an increased RR of discharge to home post-PPS (compared to prePPS of 1.(15. the population of (hoth Medicare and non-Medicare) residents in certified SNFs had an even higher (1.16) RR for discharge to home following the implementation of PPS.

Residents with a Medicare payment source had a RR of discharge to home of 1.84 relative to non-Medicare residents. The RR of .86 on the Medicare-PPS interation term (D) 2 estimator) indicates that the difference between Medicare and non-Medicare residents shrank 10 ) 1.58 (1.84 $\times$ .86) in the post-PPS period. Thus the galp between Medicare and non-Medicare resident dischatrges was reduced following the implementation of PPS.

In the full population. the risk of discharge to other destinations did not change significanty from the pre-PPS to the post-PPS period. The Medicare palyment source RR estimates indicalle that for residents admitled with Medicare als their payment source, the relative rish of discharese within 120 days to all destinations was 1.45 to 1.91 times higher that of non-Medicare residents. The Medicare PPS difference-in-differences (D2) estimallor shows that the PPS proeram reduced the RR of discharge to death for Medicare residents relative to other residents. The relative risk of hospitalization and transfer for Medicate residents in the post-PPS period wats also less than 1.(). but not significant.

Sensinivity Analyses

Several semsitivity analyses were conducted. These results are too numerous to display, but are available from the first author on request. 


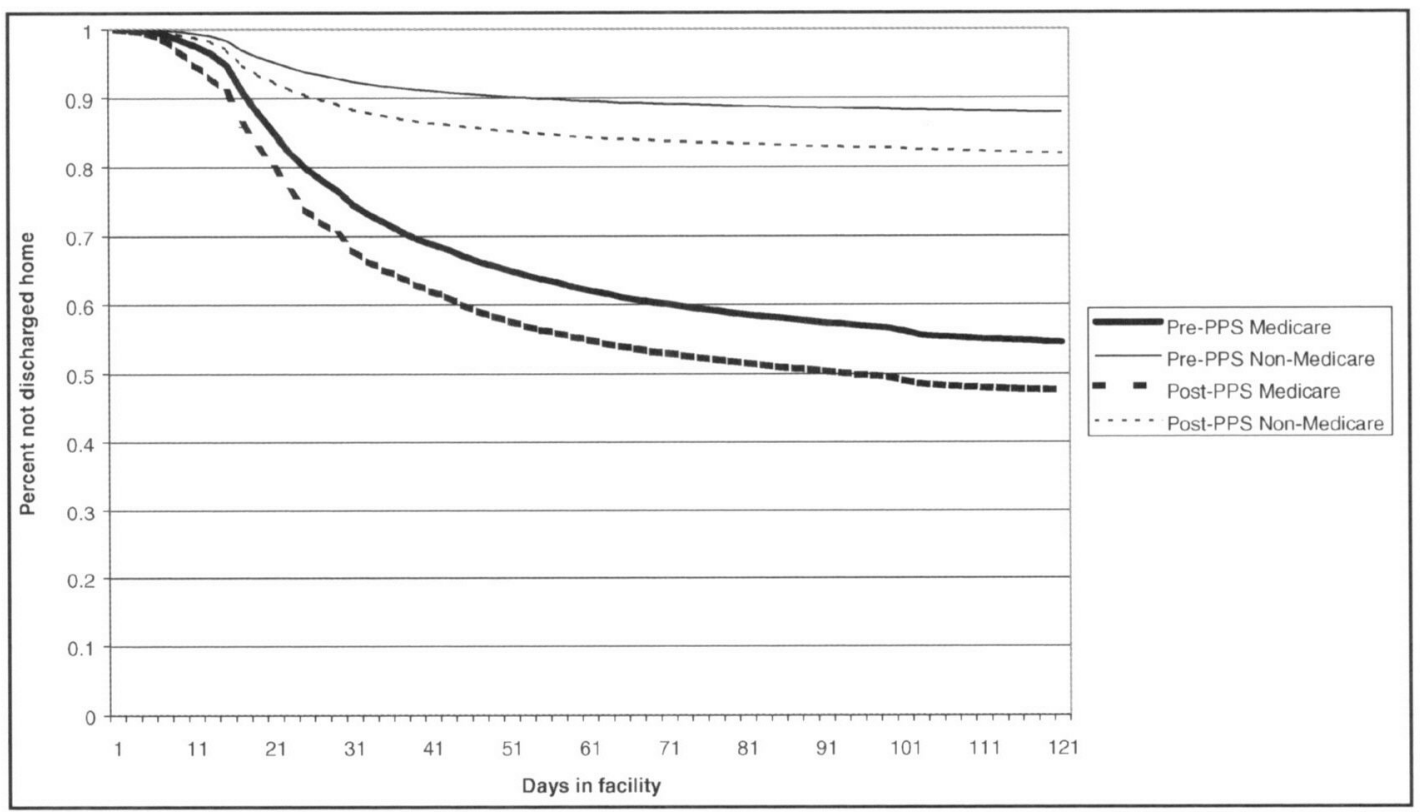

Figure 1. Survival before discharge home

The first analysis identified tixed-market effects for all counties in the two states. In the Medicare-only population, these results indicated an RR of 1.13 (compared to 1.05). Similarly the RR for discharge to home in the overall sample in- creased from 1.16 10 1.22. The D2 (Medicare post-PPS) estimate was .88 . thus providing analogous overall results to those presented in Table 3. The largest difference in a RR point estimate was a reduction in the $R R$ for transfer of residents with

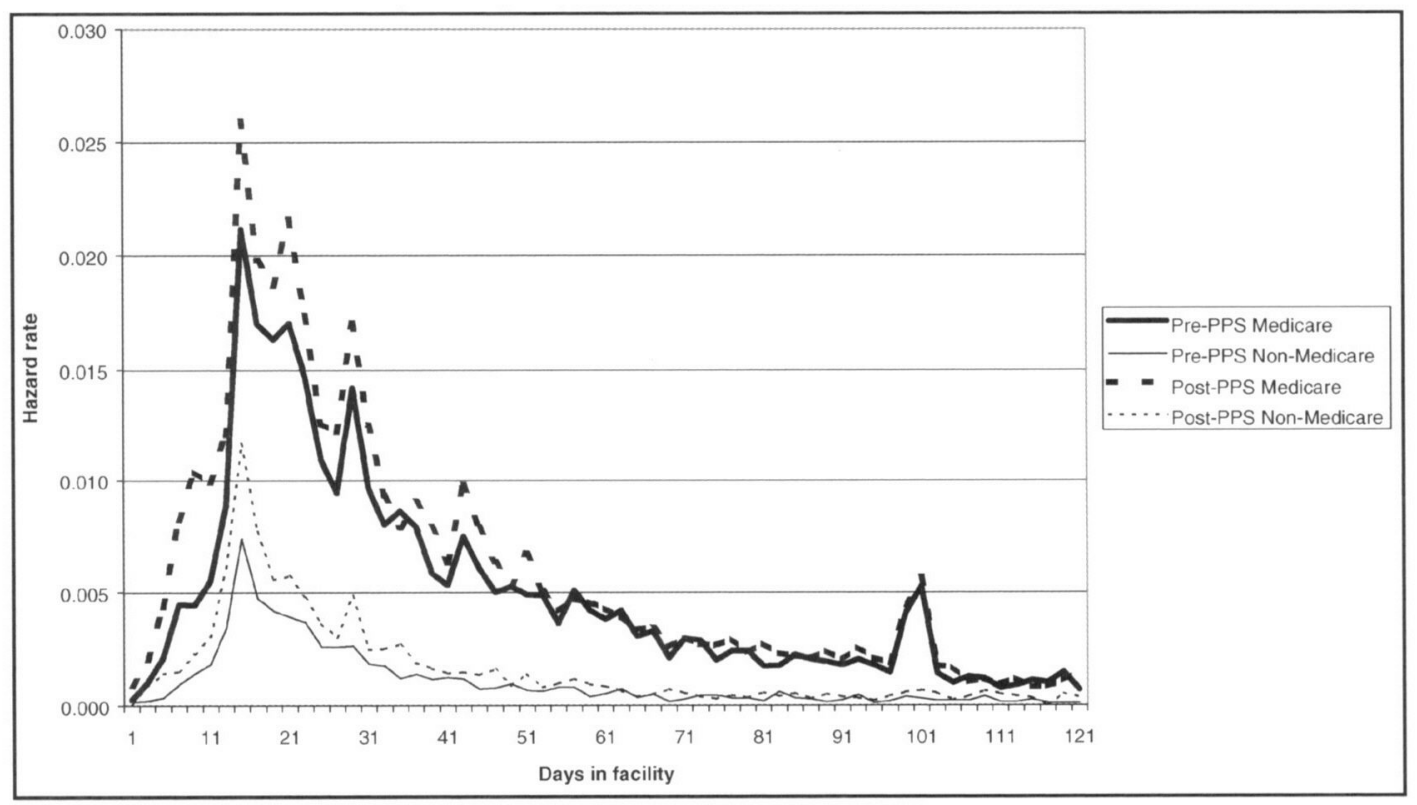

Figure 2. Hazard for discharge home 


\section{Table 3. Medicare and full population: relative risk for each discharge destination}

\begin{tabular}{lcccc}
\hline & \multicolumn{3}{c}{ Discharge destination relative risk } \\
\cline { 2 - 5 } & Home & Hospital & Death & Transfer \\
\hline Medicare sample only & & & & \\
$\quad$ Post-PPS period & $1.05^{* *}$ & .99 & $.92^{* *}$ & $1.07^{*}$ \\
Full sample results & & & & \\
$\quad$ Post-PPS period & $1.16^{* * *}$ & .97 & 1.05 & 1.10 \\
Medicare payment source & $1.84^{* * *}$ & $1.45^{* * *}$ & $1.45^{* * *}$ & $1.91^{* * *}$ \\
$\quad$ Medicare $\times$ Post-PPS (D2) & $.86^{* * *}$ & .96 & $.81^{* * *}$ & .93 \\
\hline
\end{tabular}

Note: Model adjusts for continuous time and all resident, facility, and market indicators from Table 2. $* * * p<.001$.

$* * p<.01$

$* p<.05$.

"Medicare payment source" where the estimated risk decreatsed from 1.91 to 1.82 . The relative risk estimates for the test of our hy pothesis. namely the "Medicare $\times$ post-PPS (D2)" increased for calch destination by (0) or (0). The latter results indicate that the effect of PPS on Medicalle resident discharges was only slightly affected by market-level lictors not identitied in the base model.

The D2 result is the parameter that tests our hypothesis. Thus, for brevity. hereafter we discuss only chitnges in the Medicare post-PPS (D2) estimales. Only magnitude changes are described becaluse there were no changes to the reported significance levels. The second sensitivity analysis compared the use of a $10(1-$ daly observation period. These results again provided analogous results with the D2 RR estimate increasing by between .0 and .03. The third analysis compared the use of the first (instead of at random) resident slay for residents with multiple SNF admissions. The sludy start date wals deferred for 120 days in this analysis to allow for a "Jook-back" period to ensure our lirst admission sample did not include residents who had had recent mursing home stalys. These results provided lower RRs for discharge (1) home 1.84 instead of .86), and for discharge to death (.77 instead of . 81 ). These values suggest that Table 3 results provide a lower bound on the effect of PPS for Medicare resident outcomes.

The proportion of a facility sevenues from Medicare could increase facility sensitivity to the change in payment system for Medicare residents. Becalluse specialization in Medicare residents iscollincalr with payment source, sensitivity analy ses were conducted to assess the importance of the proportion of Medicare palyment to the facil- ily. This antlysis wats based on facilities with less than 2.5\% Medicare residents (lowest quartile). between 2.5\% and 12.5\% Medicare residents (inter-quartike range), and more than $12.5 \%$ Medicare residents. The full analyses were run on each of these subpopulations of residents. The effect of PPS on discharge home within each subsample increased with increasing prevalence of Medicare residents (not significant for residents in the lowest quattile, $\mathrm{RR}=.85 \mathrm{in}$ "mixed" inter-quartile range, and $R R=.80$ in the "Medicare specializing" facilities with more than $12.5 \%$ ). Thus, as expected, facilities that depended more heavily on Medicare revenues were more sensitive to the changes alssociated with PPS.

Results also were examined based only on residents aldmitted directly from the hospital to the SNF (reducing the Medicare simple by 19\% and the non-Medicare sample by $66 \%$ ). The changes in the RR for Medicare PPS (D2 estimator) were .87 for discharge 10 home, or just (0) higher than the full sample result, and .0.3 lower for discharge to death. Selecting a post-icute sample had a more substantial effect on the RR associated with Medicare payment source on discharge to home. This RR was reduced to 1.61 (.23 lower than full sample results in Table 3), while the association between Medicare payment and the RR for discharge to hospital, death, and transfers were reduced $101.35,1.41$, and 1.89 , respectively .10, (04, and ()2 lower than Table 3 results. Finally, we examined the potential for bias in Table 3 results due to potential endogencity of occupancy rate and payer mix by excluding these chatacteristics. and we found that all relative risk point estimates for the D2 estimator were within .02. 
Sensitivity analyses also examined the imporlance of the payment source reference category (non-Medicare) by identifying Medicaid payment source in the regression model. Although the additional payment indicator variable was significant in the tinal model (with Medicaid residents having a lower relative risk of discharge than private-pay residents), all estimates of the relative risk for the Medicare PPS difference-in-differences estimator were within the 95\% contidence interval of the balse results when the additional payment source indicator variable was included in the regression model.

\section{Discussion}

This study provides the most detailed intormation 10 date on resident discharge outcomes following the implementation of PPS for Medicare Parl A SNF stays. The results should be of particular interest to policymakers monitoring the effect of PPS on resident outcomes. We find that PPS reduced the redative risk for discharge to home and for discharge to death among Medicare residents compared to non-Medicare residents. Thus PPS is associated with neither uniformly declining standards of care nor a large improvement in eflectiveness

We hypothesized that the Medicare PPS program would reduce the care provided in the SNF and that Medicare resident outcomes would deteriorate ats a result. This would lead to delayed discharges to home for Medicare residents. white deaths and discharges to hospitals could be more prevalent and occur sooner. The D2 estimator provides the direct evidence for this change. We found that while all residents experienced an increased relative risk for discharge to the community during the time period studied. Medicare residents had al reduced relative rish of discharge to home and death compared to non-Medicare residents in the post-PPS period. PPS paynum can be seen to have had a negative effect. holding back Medicare residents from experiencing the sime level of increase in the RR of dischatrge to home as non-Medicare residents. Similarly PPS payment has reduced the gap in the relative risk of discharge that exists between the shorter-stay Medicare and longer-stay non-Medicare populations. Inder an alternative interpretation. if the increased relative risk for discharges among all residents indicates that residents are being dis- chareed "quicher and sicher." then PPS has helped to protect Medicare residents from the deterioration in standards of calre.

The reduced relative risk for discharge to death suggests quality of care for Medicare residents may have improved for residents most at risk for death. Hospitalizations. another indicator of negalle outcomes, was unalfected by the change 1o PPS. Thus. using discharges as an oulcome measure of the Medicare SNF benetit. PPS appears nor to have unambiguously and seriously harmed Medicalte residents.

The restriction on Medicare payment rates maty have decreased unobserved subsidies to other payer groups, and while Medicate resident care was protected. the quality of care provided 10 non-Medicare residents diminished. If unohserved subsidies have changed under PPS. We identify a lower bound on the effect of PPS on Medicare SNF care. The role of cross-subsidizatlion in this marketplace is an open empirical issuce. The present study examined only outcomes depending on the payer responsible for care on admission. Changes in payers throughout the period of exposure (first 120 dalys of SNF care) are not addressed by this study. However. given average length of stay of 30 to 50 days. We expect little impace on the results hown here. Without any reliable source of information on payment changes during the first thee montles of a resident's stay. We used semsitivity analyses 10 indicate any potential impacts: first ensuring the full 100 days of Medicare benetits were available by selecting only first SNF admiscioms: and second, by limiting the follow-up period to the tirst 10) days post-admission.

The pattern of SNF admissions and dischatrges varies for different population groups. For example. it is a common pattern for nursing-home residents who are Medicare beneficiaries and hospitalised for an illness or injury to have a posthospitil SNI: stity conced by Medicalle olten (though not always) in the same $S N F$. Al the end of Medicare utilization (which maty be affected by payment factors. like the copaly amount. as well as by coverage criteria). they return to their previous living situation - a non-Medicare bed in a SNF-certified facility. The dynamics of SNF episodes is not addressed by our research. We found interim hospitalizations were not uncommon in our data and intend to pursue the definition of SNF "episodes of care" in future research. 
Our evidence reflects the eyperience of Medicare SNF residents amid concerms ralsed by others that rembursement for complex medical calle wals insulficiont under PPS to ensure adequate yuality of catre (Angelelli et al. 20)2: Oftice of Inspector (ieneral 1909. 2001). While the lite ter studics were unable to demonstrate changes in admission patterns, ongoing research suggests that PPS had a negative impact on other quality of care outcomes for Medicare residemes (Hod lewsty 2002). Others have found that SNFs ne sponded to PPS by optimizine treatment levels (Woklchis 2004: Wodkhis, Fries and Pollach 20(4) and improving reventes (White 2003).

The results presented in this reseatrch are based on only the tirst year of PPS payment. The CMS implementation of PPS was staged so that facilits reimbursement would be plased in over fout years (described in endnote 2). In the first year. only one-quarter of most lacilities reventues wats based on the PPS rates, whle thee-quatrees wals balsed on retrospectice couls. Monitoring fiacility response to the payment change over the four-year implememtation of PPS will provide increatsed understanding of changes in resident treatment and outeomes. As is oflen the calse. seycral studies are required to appreciate the impalet of PPS on resident cuality of care and outcomes

In the present study, the effect of the change to PPS for Medicare residents is measured with a difference-in-differences estimator. This estimator calptures all changes that were associated with Medicare residents (only) and occurred alter the change to PPS payment. This includes the use of the RU(i-lll calse-mix classification system. the prospectively determined payment rates. and a reduction in betal progaram payments. Our model posits that SiVf providers were directly allfected by the change to PPS payment and that the resident outcomes observed here were secondary outcomes (i.e. changes in resident outcomes resulted from changes in provider behavior). Any changes in facility behavior to restrict tratment costs, such as reducing medication use, resident rehabilitation treaments. or activity programming. were captured in the D2 estimator. Thus. the present study does not proside empirical es idence lor which provider behavior changes are most sensitive to the change in payment and which are most responsible for the change in Medicare resielent outcomes. Moreover, our re- sults do not specifically identify within-ficility effects. Even in sensitivity analyses, our results only identify the effect of PPS on resident carc within markets. controlling for li sed facility charackristics. Futher investigation of facility-level changes is an important extension to the results presented here.

Delays in discharges to home for Medicare residents following PPS alse may be related 10 changes outside the nursing-home marke. Between 1997 and 1099. Medicare home health benefits declined by more than 50\% (McCall et al. 20(0)1). The observed delay in discharees 10 home in this study maly be due in part to reductions in home-based support.

The data for this reseated were extracted from a large administrative databalse. Electronic databases are generally subject lo source data probkms. errors in initial coding. and electronic submission errors. among other things. However, such datal also tends to be of higher cuality when used for payment purposes, as is the case for the MDS database. This research does not assess latcility-secific costs, reimhursement, or efficiency. A lull accounting for Medicare SNF. hospital. physician. and home health care costs. as well as long-term resident outcomes, would be required to assess any change in overall afliciency of the Medicare program. Because the present study does not include facility-specific changes in total Medicare rembursement. the effect of PPS captures both changes in allocation of payment among residents in the facility and a reduction in total Medicare expenditures for SNF care. CMS continued to update and increase reimbursement rates under PPS following the period studied here. These changes provide additional sources of identification to isolate the effects of the case-mix palyment method from the elfect of changes in reimbursement rates (prices).

Evaluating the implementation of PPS and refinements to the RUG-III payment system is an ongoing concern. The present research identified changes in resident discharge outcomes as a result of PPS. Other clinical quality of catre and resident outcomes, such as the incidence of pressure sores, resident functional status and resident quality of life, shoukd be examined to ensure that resident calre is not compromised ats a result of increased federal control over expenditures. 


\section{Notes}

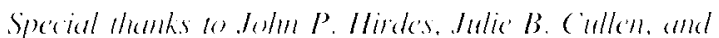

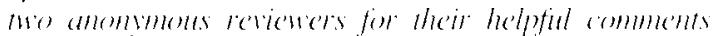

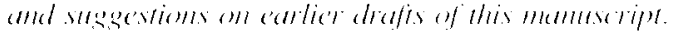

1 Medicare Parl A benerits are refered to simply as Medicare benefits throughout this text. Medicatre expenditures for SNF care an provided through Part A benefits for up to 100 datys of SNF care for residents who are admitted to a SNF withio 30 days of a discharge following at least three datys of hospital care. For residents who are not eligible for Pant A bencefis and pay lor supplementary med- ical insurance. Mecticare Part $B$ benclits coned physician visits and ancillary treatments (c.e. phy sical theraply or oryeen therapy thall are also avalable to elderly beneficiaries who live in the communits.

2 The fult implementation of Medicare PPS provides a four-year transitional period with a hlended funding formula. In the first year of PPS. 25\% of falcility reimbursement was based on case mix and $75 \%$ batsed on the old reasonable cost method: in subsequent years the case-mix proportion rose to $50 \%$ \% $75 \%$ and tinally $100 \%$ in the fourth year.

\section{Appendix Table 1. Medicare sample only results: competing-risks hazard regression}

\begin{tabular}{|c|c|c|c|c|c|}
\hline & \multicolumn{4}{|c|}{ Discharge destination relative risk } & \multirow[b]{2}{*}{. } \\
\hline & Home & Hospital & Death & Transfer & \\
\hline Post-PPS period & $1.05 * *$ & .99 & $.92 * *$ & $1.07^{*}$ & \\
\hline Admitted from hospital & $2.74 * * *$ & $1.22 * * *$ & $1.14 * * *$ & $2.52 * * *$ & \\
\hline Admitted from SNF & $.82 * *$ & 1.04 & 1.03 & 1.18 & \\
\hline Male & $1.05 * * *$ & $1.31 * * *$ & $1.54 * * *$ & $.94 *$ & \\
\hline $75-84$ & $.85 * * *$ & $.87 * * *$ & $1.29 * * *$ & $1.32 * * *$ & \\
\hline $85+$ & $.59 * * *$ & $.75 * * *$ & $1.66^{* * *}$ & $1.53 * * *$ & \\
\hline Impaired $(\mathrm{CPS}=2,3,4)$ & $.46 * * *$ & $.91 * * *$ & $1.37 * * *$ & 1.01 & \\
\hline Totally dependent $(\mathrm{CPS}=5,6)$ & $.27 * * *$ & $.89 * * *$ & $2.22 * * *$ & $.84 * * *$ & \\
\hline Impaired $(\mathrm{ADL}=2,3,4)$ & $.69 * * *$ & $1.30 * * *$ & $1.94 * * *$ & $.79 * * *$ & \\
\hline Totally dependent $(\mathrm{ADL}=5,6)$ & $.48 * * *$ & $1.59 * * *$ & $3.87 * * *$ & $.66^{* * *} *$ & \\
\hline RUG-III case-mix index & $1.18 * * *$ & $.96 * * *$ & $.81 * * *$ & $1.06 * * *$ & . \\
\hline Recent fall (<180 days) & $.88 * * *$ & $.87 * * *$ & $.84 * * *$ & $1.14 * * *$ & \\
\hline Bedfast & $.64 * * *$ & $1.12 * * *$ & $2.17 * * *$ & 1.03 & \\
\hline Pressure ulcer & $.88^{* * *}$ & $1.11 * * *$ & $1.09 * * *$ & $.92 * * *$ & \\
\hline Cerebrovascular accident (stroke) & $.84 * * *$ & $.90 * * *$ & $.88 * * *$ & 1.00 & \\
\hline Alzheimer's disease & $.62 * * *$ & $.78 * * *$ & $.75 * * *$ & 1.03 & \\
\hline Oxygen therapy & .98 & $1.40 * * *$ & $2.23 * * *$ & 1.04 & \\
\hline Indwelling catheter & $.86 * * *$ & $1.09 * * *$ & $1.25^{* * *}$ & $1.10 * *$ & \\
\hline Feeding tube & $.68 * * *$ & $1.17 * * *$ & $.67 * * *$ & $.71 * * *$ & \\
\hline Total beds & $1.03 * * *$ & 1.01 & 1.00 & $1.04 * * *$ & \\
\hline Occupancy rate & $.75 * * *$ & $.77 * * *$ & $1.42 * * *$ & $.60^{* * *}$ & \\
\hline For-profit ownership & .98 & $1.08 * *$ & .98 & .95 & \\
\hline Chain membership & $.92 * * *$ & 1.01 & 1.00 & 1.00 & \\
\hline Facility is hospital-based & $1.55 * * *$ & 1.01 & .98 & $2.09 * * *$ & \\
\hline$>7 \%$ Medicare & $.94 * *$ & 1.02 & $.93 *$ & $.91 * *$ & \\
\hline$>12 \%$ Medicare & $1.16^{* * *}$ & $1.13^{* * *}$ & $.91 * *$ & $1.35 * * *$ & \\
\hline$>65 \%$ Medicaid & $.86^{* * *}$ & 1.02 & .97 & $.79 * * *$ & \\
\hline$>77 \%$ Medicaid & $1.06^{* *}$ & $1.09 * *$ & $.83 * * *$ & 1.08 & \\
\hline $\mathrm{RN}>6 / 100$ residents & $1.15^{* * *}$ & 1.02 & .99 & $1.09 *$ & \\
\hline $\mathrm{RN}>8 / 100$ residents & $.93 * * *$ & 1.02 & .96 & .96 & \\
\hline $\mathrm{RN}>12 / 100$ residents & $1.39 * * *$ & .97 & .99 & $1.36 * * *$ & \\
\hline LPN \& LVN > (10/100) residents & .97 & 1.00 & .99 & $1.16 * * *$ & \\
\hline LPN \& LVN > (14/100) residents & $1.09 * * *$ & 1.00 & .95 & $.92 *$ & \\
\hline LPN \& LVN > (18/100) residents & 1.04 & 1.05 & 1.07 & 1.05 & \\
\hline Health aides $>35 / 100$ residents & .98 & $1.09 * *$ & .99 & 1.02 & \\
\hline Health aides $>41 / 100$ residents & .99 & .96 & 1.06 & 1.01 & \\
\hline Health aides $>49 / 100$ residents & $.96 *$ & .95 & .95 & .98 & \\
\hline
\end{tabular}


Appendix Table 1. (continued)

\begin{tabular}{lcccc}
\hline & \multicolumn{3}{c}{ Discharge destination relative risk } \\
\cline { 2 - 4 } & Home & Hospital & Death & Transfer \\
\hline Ohio & $1.71 * * *$ & $1.34 * * *$ & $1.10^{* *}$ & $1.59 * * *$ \\
Market competition & $.85 * * *$ & $2.23 * * *$ & .87 & $1.92^{* * *}$ \\
Market wage index & $.68^{* * *}$ & 1.24 & $.62 * *$ & $.42 * * *$ \\
Time trend & $1.01 * * *$ & $1.01 * * *$ & $1.01 * * *$ & $1.01 * * *$ \\
\hline
\end{tabular}

$* p<.05$.

$* * p<.01$.

$* * * p<.001$.

Appendix Table 2. Full results: competing-risks hazard regression

\begin{tabular}{|c|c|c|c|c|}
\hline & \multicolumn{4}{|c|}{ Discharge destination relative risk } \\
\hline & Home & Hospital & Death & Transfer \\
\hline Medicare & $1.84 * * *$ & $1.45 * * *$ & $1.45 * * *$ & $1.91 * * *$ \\
\hline Post-PPS period & $1.16^{* * *}$ & .97 & 1.05 & 1.10 \\
\hline Medicare* Post-PPS (D2) & $.86 * * *$ & .96 & $.81 * * *$ & .93 \\
\hline Admitted from hospital & $3.34 * * *$ & $1.37 * * *$ & $1.21 * * *$ & $2.58 * * *$ \\
\hline Admitted from SNF & $.71 * * *$ & $1.11 *$ & 1.00 & $1.18 * *$ \\
\hline Male & $1.06 * * *$ & $1.31 * * *$ & $1.52 * * *$ & .98 \\
\hline $75-84$ & $.83 * * *$ & $.88 * * *$ & $1.24 * * *$ & $1.28 * * *$ \\
\hline $85+$ & $.58 * * *$ & $.78 * * *$ & $1.62 * * *$ & $1.45^{* * *}$ \\
\hline Impaired $(\mathrm{CPS}=2,3,4)$ & $.45^{* * *}$ & $.89 * * *$ & $1.31 * * *$ & .98 \\
\hline Totally dependent $(\mathrm{CPS}=5,6)$ & $.26 * * *$ & $.87 * * *$ & $2.09 * * *$ & $.80 * * *$ \\
\hline Impaired $(\mathrm{ADL}=2,3,4)$ & $.69 * * *$ & $1.27 * * *$ & $1.91 * * *$ & $.78 * * *$ \\
\hline Totally dependent $(\mathrm{ADL}=5,6)$ & $.48 * * *$ & $1.54 * * *$ & $4.14 * * *$ & $.65 * * *$ \\
\hline RUG-III case-mix index & $1.29 * * *$ & 1.00 & $.83 * * *$ & $1.11 * * *$ \\
\hline Recent fall (<180 days) & $.89 * * *$ & $.89 * * *$ & $.89 * * *$ & $1.14 * * *$ \\
\hline Bedfast & $.65 * * *$ & $1.09 * *$ & $2.25 * * *$ & 1.06 \\
\hline Pressure ulcer & $.89 * * *$ & $1.13 * * *$ & $1.11 * * *$ & $.92 * * *$ \\
\hline Cerebrovascular accident (stroke) & $.84 * * *$ & .97 & $.91 * * *$ & 1.02 \\
\hline Alzheimer's disease & $.64 * * *$ & $.87 * * *$ & $.79 * * *$ & 1.03 \\
\hline Oxygen therapy & 1.00 & $1.49 * * *$ & $2.38 * * *$ & 1.03 \\
\hline Indwelling catheter & $.86 * * *$ & $1.13^{* * * *}$ & $1.26 * * *$ & $1.10 * * *$ \\
\hline Feeding tube & $.68 * * *$ & $1.14 * * *$ & $.64 * * *$ & $.72 * * *$ \\
\hline Total beds & $1.03 * * *$ & 1.01 & .98 & $1.04 * * *$ \\
\hline Occupancy rate & $.74 * * *$ & $.80 * * *$ & $1.39 * * *$ & $.60 * * *$ \\
\hline For-profit ownership & .98 & $1.11 * * *$ & .99 & .97 \\
\hline Chain membership & $.94 * * *$ & 1.00 & .98 & 1.00 \\
\hline Facility is hospital-based & $1.54 * * *$ & 1.00 & 1.00 & $2.11 * * *$ \\
\hline$>7 \%$ Medicare & $.96 * *$ & 1.02 & $.94 *$ & .95 \\
\hline$>12 \%$ Medicare & $1.15 * * *$ & $1.11 * * *$ & $.91 * * *$ & $1.29 * * *$ \\
\hline$>65 \%$ Medicaid & $.86 * * *$ & 1.03 & .97 & $.78 * * *$ \\
\hline$>77 \%$ Medicaid & 1.04 & $1.10 * * *$ & $.83 * * *$ & 1.06 \\
\hline $\mathrm{RN}>6 / 100$ residents & $1.15 * * *$ & 1.01 & 1.03 & $1.07 *$ \\
\hline $\mathrm{RN}>8 / 100$ residents & $.92 * * *$ & 1.02 & .98 & .98 \\
\hline $\mathrm{RN}>12 / 100$ residents & $1.38 * * *$ & .99 & .98 & $1.30 * * *$ \\
\hline LPN \& LVN > (10/100) residents & .97 & .96 & .98 & $1.14 * * *$ \\
\hline LPN \& LVN > (14/100) residents & $1.10 * * *$ & 1.04 & .96 & $.94 *$ \\
\hline LPN \& LVN > (18/100) residents & 1.00 & 1.04 & 1.03 & 1.01 \\
\hline Health aides $>35 / 100$ residents & .98 & $1.08 * *$ & .99 & 1.01 \\
\hline Health aides $>41 / 100$ residents & .99 & .97 & 1.04 & 1.03 \\
\hline Health aides $>49 / 100$ residents & .98 & .96 & .97 & 1.00 \\
\hline Ohio & $1.83 * * *$ & $1.37 * * *$ & $1.10^{* *}$ & $1.63^{* * *}$ \\
\hline Market competition & $.83 * * *$ & $2.26 * * *$ & .98 & $1.93 * * *$ \\
\hline
\end{tabular}




\begin{tabular}{lcccc}
\hline & \multicolumn{3}{c}{ Discharge destination relative risk } \\
\cline { 2 - 5 } & Home & Hospital & Death & Transfer \\
\hline Market wage index & $.77 * *$ & 1.20 & $.58 * * *$ & $.43^{* * *}$ \\
Time trend & $1.01 * * *$ & $1.01 * * *$ & $1.01 * * *$ & $1.01 * * *$ \\
\hline
\end{tabular}

$* p<.05$.

$* * p<.01$.

$* * * p<.001$

\section{References}

Angelelli. J., D. Gifford. O. Intrattor. P. Gomalo, I. Lalibente. and V. Mor. 2002. Access to Postacule Nursing Home Care before and atter the BBA Health Affuirs 21:254-264.

Arling. G., A.R. Williams, and D. Kopp. $2(0) 0$. Therapy Use and Discharge Outcomes for Elderly Nursing Home Residents. Gerontologist $40: 587-595$

Banasyak-Holl, J., J.S. Zinn, and V. Mor. 1096. The Impact of Market and Organizational Characteristics on Nursing Care Facility Service Innovation: A Resource Dependency Perspective. /leallh Services Resedreh 31:97-117.

Bratun, B.l. 1991. The Effeed of Nursing Home Quality on Patient Outcome. Jommal of the American Geriatrices Soriets 39:329-338.

Centers for Medicare and Medicaid Services (CMS). 1999. Cor Parts 409, 411. 413, and 489 Medicano Program: Prospective Payment System and Consolidated Billing for Skilled Nursing Fateilities Update: Final Rule and Notice. Federal Register $64: 41680$.

2004a. Nusine /lome Compare. Available at: htup://www.medicare.gov/NHCompare/Home.asp Accessed March 19

_.... 2004b. Table 13: Nursing Home Care

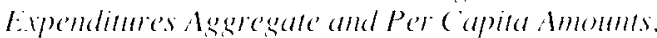

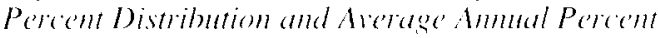
Change by Somber of Funds: Selected Calendal Years 1980-2012. Available all: hatp://www. cms.hhs.gov/statistics/nhe/projections-2002/ 113.asp Accessed March 19.

Cohen. J., and W. Spector. 1996. The Effect of Medicaid Reimbursement on Quality of care in Nursing Homes. Joumal of Ilealth Eamomics 15:23 18.

Cohen. J.W. and I.C. Dubay. 1990). The Effects of Medicaid Reimbursement Method and Ownership on Nursing Home Costs, Case Mix, and Stafting. Incyimiry 27:183-20().

Cohen-Mansfield, J., M.S. Marx, S. Lipson, and P. Wence. 1999. Predictors of Mortality in Nursing Home Residents. Ionnal of Clinical Epidemiol (e). 52:273-280.

Engle, V.F., and M.J. Graney. 1993. Predicting Outcomes of Nursing Home Residents: Death and Discharge Home. Jommal of (jerontologe 48 : S269-S275.
Frederiksen, K.. P. Tariot, and F. De Jonghe. 1006 Minimum Data Set Plus (MDS+) Scores Compared with Scores from Five Rating Scalces.

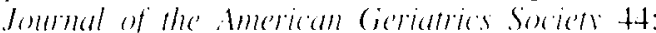
$305-309$

Fries, B.E., D.P. Schneider. W.I. Foley. M. Givarri. el al. 1994. Relining a Calse-Mix Measure for Nursing Homes: Resource Eltilization Ciroups (RUG-IIl). Medical Care 32:068-685.

Garber. A. and T. Macurdy. 1993. Nursing Ilomo Dischareses and Exhaustion of Medicare Benetits.

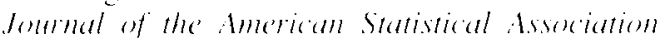
$88: 727-736$

Grabowski. D.C. 2001a. Does an Increalse in the Medicaid Reimbursement Rate Improve Nursing

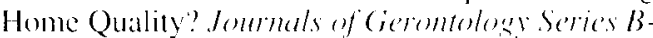

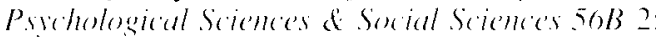
$\mathrm{Sit}-93$

- 2001b. Medicatid Reimbursement and the Quality of Nursing Home Care. Jommal of /leall Ecomomic: 20:549-569.

Harrington. C.. H. Carillo. S. Thollate, P. Summers. and V. Wellin. 20o(o). Nursins facilities. Staffins.

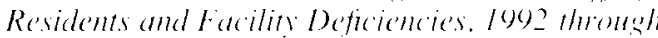
Jog8. University of California. San Franciseo.

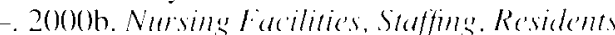

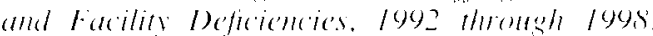
University of Califomia. San Francisco.

Harrington. C.. J. Swan. V. Wellin. W. Clemena. and H. Carrillo. 1998. State Date Beseh on Loms Term

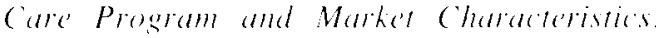
Washingtom, D.C.: CMS

Hanmaier. S.L.. P.D. Sloanc. H.A. Ciness. G. i. Koch. a al. 1995. Validation of the Minimum Data Set Cognitive Perlormance Scale: Agreement with the Mini Mental State Exammation. fentruls of

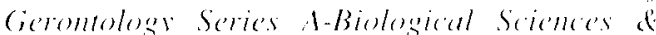
Medical Seriene's 2:MI28-M133.

Hawes, C.. J.N. Morris, C.D. Phillips, V. Mor, B.I: Fries, and $S$. Nonemaker. 1995. Reliability Estimates for the Minimum Data Set for Nursing Home Resident Assessment and Care Screening (Mds). Cicrentelosist 35:172--178

Hodlewsky. R.T. 2002. Effects of Medicare's Prospective Payment System on Quality of Care in Nursing Facilities. (iementolegist 42:234.

Hutt. E.. M. Ecord. T.B. Eilertsen. E. Frederickson. J.C. Kowalsky. and A.M. Kramer. 2001. Prospective 
Payment for Nursing Homes Increased Theraps Provision withoul Improving Community Dos

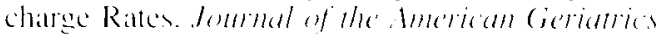
Seriely f9: $1071-1079$.

Mecall. N. H.l. Komisate. A. Petersons, and $S$ Monere. 20001. Medicare Home Health before and alter the BBA. Heallh Affairs 20:180.. Jos.

Medicare Payment Advisory Commission (Med-

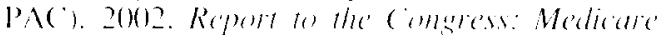
Pament Pralicy. Washington. D). ( $\therefore$ MedPAC.

Morris, J.N. B.E. Jries. D.R. Mehr. C. Hawes. C. Phillips. V. Mor. and L..A. Lipsite 1094. MDS

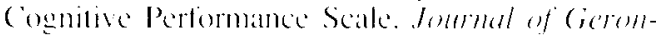
tologe +9.217+-182.

Morris, J.N. B.l. Fries, and S.A. Morris. 1909. Scaling ADl.s within the MIOS. Jentmals of

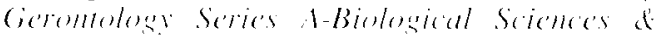
Medical Sithers 54:M540-553

Morris. J.N. S. Nonemaher. K. Murphy, C' Hawes. B.l. Pries, V. Mor, and ('. Phillips. 1007. A Commiment of chanec: Revision of HCTA:

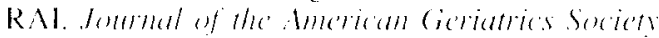
$45: 1011 \cdots 1016$.

Oflice of Inspector (iencral. 1909. Larth tiffers of the

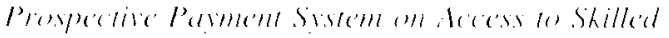

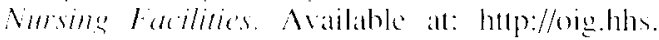
gov/oci//reports/attos pelf Acoessed Feb. 10. $2(x) 2$.

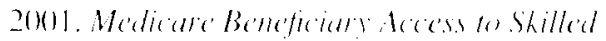
Nuring facilitios Avaliable at: hop:/oighbs.

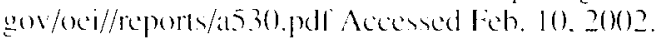

Porell, F., F. (i. Caro, A. Silval, and M. Monance 1998 A Longitudinal Analysis of Vursing Home (outcomes. Health Services Rexeeme/h 3.3:83.5-86.5.

Soadari. A. J.A. Morris. B.E. Fries. (i. l jungeren. P.V. Jomsson. J. DuPalquier, and M. Schroll. 1997. Efforts to Establish the Reliathility of the Resident Assessment Instrument. Age de fering 26:27-30.

White. (. 2003. Rehabilitation Therapy in Skilled Nursing Facilities: Effects of Medicare's New Prospective Payment System. Ilealth Affairs 22: $21+233$

Williams. B.C'. B.E. Fries, W.J. Foley, 1). Schneider. and M. Ciavardi. 1994. Activities of Datly Living and Costs in Nursing Homes. /lealh Care Findmethe Rellew 15:117-135.

Williams. B.C.. Y. L.i. B.F. Frics. and R.L. Wamen. 1997. Predicting Patient Scores between the Functional Independence Measure and the Minimum Data Set: Development and Perfommance of a FIM-MDS "Crossualk." Arehires of Phssical Medicine de Rehabilitution 78:48-54.

Wodchis. W. 20(14. Physical Rehabilitation Following Medicare Prospective Payment for Skilled Nurs ing Facilitics. Healh Sorvices Resenth 39:12751295 .

Wodchis, W.. B.F. Fries, and H. Pollack. 20(04. Payer Incentives and Physical Rehabilitation Therapy for Nonclderly Institutional long-Term care Residents: Evidence from Michigan and Ontario.

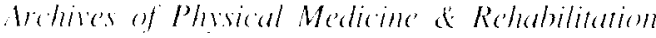
$85: 21010217$. 